\title{
Physi-Chemical Property Research of Polysaccharides from Pomegranate Flowers
}

\author{
Lixin Peng1,2, Yizhao Huang1, Wei Tan1, Zhiwei Wei', Lihua Zhang1* \\ ${ }^{1}$ Zaozhuang University, Zaozhuang, China \\ ${ }^{2}$ International Center for Bamboo and Rattan, Beijing, China \\ Email: *chinazhanglh@163.com
}

How to cite this paper: Peng, L.X., Huang, Y.Z., Tan, W., Wei, Z.W. and Zhang, L.H. (2021) Physi-Chemical Property Research of Polysaccharides from Pomegranate Flowers. Journal of Materials Science and Chemical Engineering, 12, 59-67.

https://doi.org/10.4236/as.2021.122005

Received: January 11, 2021

Accepted: January 28, 2021

Published: February 4, 2021

\begin{abstract}
Pomegranate flowers as row materials were used for extraction of polysaccharides by water-extraction and alcohol-precipitation method. After purification, the physical and chemical properties, structure, monosaccharide composition and molecular weight were studied. The results showed that the polysaccharides from pomegranate flowers mainly contained two kinds of water soluble acidic polysaccharides, and monosaccharide composition were arabinose and galactose, both contained hydroxyl, carboxyl, amino, hydroxyl radical, sulfate, beta glycosidic bond and alpha glycosidic bond structure. The molecular weight of PP1 and PP2 were $6.16 \times 10^{4}( \pm 6.6 \%)$ and $9.01 \times 10^{4}$ $( \pm 3.2 \%)$, respectively. The results of this study laid the foundation for further development and application of polysaccharides from pomegranate flowers.
\end{abstract}

\section{Keywords}

Polysaccharides, Pomegranate Flowers, Physical and Chemical Properties

\section{Introduction}

Pomegranate flower was the floral organ of Punica granatum L., which contained polyphenols, flavonoids, three terpenoids and other components [1]. The pomegranate flowers could be used for the treatment of otitis media, epistaxis, and trauma hemorrhage as a traditional Chinese medicine [2], which had astringent taste. They were called "Gulina" in Uygur Medicine, played a role in treating slight corneal opacity, neurasthenia and nausea [3]. In addition, they also had been used in the treatment of diabetes and its complications in India [4].

Polysaccharides widely existed in nature and possessed a variety of biological activities, could be used as one of the effective constituents of Chinese herbal 
medicine. They were ideal immune enhancers [5] [6] [7], and improved the immune system's function and had no toxic or side effects on normal cells. Polysaccharides were used for the drug research of antitumor, antiviral, anti-aging, which was one of the important directions of the new medicine [8]. Therefore, the studies of extraction and biological activity of plant polysaccharides had attracted more and more attention. Currently, the research indicated that pomegranate flowers contained polysaccharide components [9], but there were few researches on polysaccharide from pomegranate flowers. In this paper, we studied the physicochemical properties, structure, molecular weight and monosaccharide fractions of purified polysaccharides from pomegranate flowers, which laid a foundation for the development and utilization of polysaccharides from pomegranate flower.

\section{Materials and Methods}

\subsection{Materials and Reagents}

Pomegranate flower was collected from Zaozhuang University campus in June 2014. Pomegranate variety is "Gangliu". The sample was dried at constant temperature of $60^{\circ} \mathrm{C}$ and stored in the refrigerator.

Phenol, sulphoacid, chloroform, isopropyl alcohol, ethanol, methanol, Coomassie brilliant blue G-250, sodium tetraborate, iodine, potassium iodide, ethyl acetate, acetic acid, acetone, ethyl ether, aniline, diphenylamine, phosphoric acid (AR); potassium bromide (SP); m-hydroxyldiphenyl, bovine serum albumin (BSA), d-galacturonic acid, glucose, rhamnose, xylose, mannose, galactose, L-Arabinose, fructose were used without further purifiaation. Blue dextran 2000 (BR); dextran T10, T20, T50, T70, T100, T200 (RT); 44 - 3500 dialysis bag, D101 resin, DEAE cellulose DE-52, Board silica gel GF254, Sephadex G-75 were used according to the instructions.

\subsection{Test Methods}

\subsubsection{Measurement of the Polysaccharide Content}

The content of polysaccharide was determined by phenol sulfuric acid method [10]. The specific steps of making the glucose standard curve were as follows: firstly, preparing $16-72 \mu \mathrm{g} / \mathrm{mL}$ of gradient standard solution of glucose, each gradient was $2.0 \mathrm{~mL}$. After adding $1.0 \mathrm{~mL}$ of $5 \%$ phenol, quickly added $5.0 \mathrm{~mL}$ of concentrated sulfuric acid and shook well. The absorbance at $490 \mathrm{~nm}$ was measured after placing $30 \mathrm{~min}$ at room temperature. The regression curve was $A=$ $0.0168 c-0.0441\left(\mathrm{R}^{2}=0.9999\right)$.

\subsubsection{Determination of Protein Content}

The content of protein was determined by Coomassie blue staining [11]. The specific steps of making protein standard curve were as follows: firstly, preparing $5-30 \mathrm{~g} / \mathrm{mL}$ of gradient BSA standard solution, each gradient was $0.1 \mathrm{~mL}$. Then added $5 \mathrm{~mL}$ Coomassie brilliant blue G-250 and shook well. The absorbance at $595 \mathrm{~nm}$ was measured after placing $10 \mathrm{~min}$ at room temperature. The regression 
curve was $A=0.9311 c-0.0055\left(\mathrm{R}^{2}=0.9972\right)$.

\subsubsection{Detection of Polysaccharide Purity}

Two kinds of polysaccharides from pomegranate flowers were separated and purified. Determine the purity of polysaccharides samples by $190-400 \mathrm{~nm}$ UV spectrum.

\subsection{Methods of Extracting and Purifying Polysaccharides from Pomegranate Flowers}

\subsubsection{Extraction Method of Crude Polysaccharide}

Mixed pomegranate flower powder with distilled water at 1:20 of solid-liquid ratio, and extracted $3 \mathrm{~h}$ at $95^{\circ} \mathrm{C}$. After anhydrous ethanol were added to get the volume fraction of $80 \%$, kept overnight static polysaccharide precipitation, filtered and dried to obtain crude polysaccharide.

\subsubsection{Sevage Protein Removal}

Preparing $5 \mathrm{mg} / \mathrm{mL}$ crude polysaccharide solution, and added sevage reagent (chloroform: $n$-butanol $=4: 1$ ) according to the proportion of 1:1. Mixing reacted $20 \mathrm{~min}$ in a separatory funnel, released the underlying sevage reagent and intermediate denatured protein. Repeated 5 times until the denatured protein did not appear and determined the protein content. The polysaccharide with low protein content was obtained by adding 2 times volume of ethanol and dried in vacuum [12].

\subsubsection{Removal of Pigment by Macroporous Resin D101}

Preparing $10 \mathrm{mg} / \mathrm{mL}$ polysaccharide solution, then added the pretreated D101 resin with 10:1 (mL/g) ratio. After being stirred for $1 \mathrm{~h}$, the resin was filtered out, and the polysaccharide solution was stored at $4^{\circ} \mathrm{C}$.

\subsubsection{Removal of Small Molecular Impurities by Dialysis}

Transferred polysaccharides filtrate to $44-3500 \mathrm{Da}$ dialysis bags, dialysed against distilled water for at least $24 \mathrm{~h}$.

\subsubsection{Classification and Purification of Polysaccharide Components}

DEAE-52 cellulose was fully dissolved in pure water, and activated by washing with hydrochloric acid of $0.5 \mathrm{M}$ and sodium hydroxide of $0.5 \mathrm{M}$. A chromato bar of $\Phi 1.6 * 50 \mathrm{~cm}$ was adopted, and the volume of the packed bed was $56 \mathrm{~mL}$. Balanced chromatographic column with $0.05 \mathrm{M}$ sodium chloride and added $2 \mathrm{~mL}$ sample of polysaccharide solution. Then eluted with a gradient of 0.05 to $1 \mathrm{M}$ sodium chloride. Controlled the flow rate was $0.5 \mathrm{~mL} / \mathrm{min}$, collected 1 tube every $10 \mathrm{~min}$. The collection solution was detected by phenol sulfuric acid method and the elution curve was drawn. Six tube eluate with centered peak were collected, then freeze-dried after dialysis.

\subsection{Analysis of Physicochemical Properties}

Weighed each polysaccharide component $10.0 \mathrm{mg}$ and mixed with $10 \mathrm{~mL}$ ultra- 
pure water, dissolved at 4 degrees overnight.

\subsubsection{Solubility Test}

The polysaccharides were dissolved in cold water, hot water, ethyl acetate, ethanol, acetone, ether, n-butanol, isopropanol, and observed the dissolution.

\subsubsection{Phenol Sulfuric Acid Test}

$1 \mathrm{~mL}$ polysaccharide solution, added phenol and sulfuric acid according to the method in 1.3.1, and observed the change of solution color.

\subsubsection{Determination of Uronic Acid Content}

The m-hydroxydiphenyl method [13] was adopted to determine the uronic acid content content. $1 \mathrm{~mL}$ polysaccharide solution was cooled in ice bath, $6 \mathrm{~mL}$ $\mathrm{B}_{4} \mathrm{Na}_{2} \mathrm{O}_{7}$ of sulfuric acid was added. Boiling $12 \mathrm{~min}$, then cooled to room temperature, $80 \mu \mathrm{L}$ of $0.15 \% \mathrm{~m}$-hydroxydiphenyl solution was added. After $40 \mathrm{~min}$, $\mathrm{OD}_{525}$ was tested and calculated the content of uronic acid, d-galacturonic acid as standard sample.

\subsubsection{I-KI Reaction}

Absorbed 5 drops of polysaccharide samples solution in the small hole of the drip plate and two drops of I-KI solution were added. Contrasted color with distilled water and starch solution.

\subsubsection{Infrared Spectrum Analysis of Polysaccharides}

Mixed and grinded the dried polysaccharide solids with $\mathrm{KBr}$ at a ratio of 1.5 to 100 and compressed to tablet. After deducting the background, the tablets were scanned infrared spectrum within the range of $397-4001 \mathrm{~cm}^{-1}$

\subsubsection{Thin Layer Analysis of Monosaccharide Composition}

Weighed $2.00 \mathrm{mg}$ sample in $5 \mathrm{~mL}$ ampoules bottle, continuous $4 \mathrm{~h}$ of acid hydrolysis reaction at $110^{\circ} \mathrm{C}$, then dried with nitrogen at $50^{\circ} \mathrm{C}$, and added $3 \mathrm{~mL}$ methanol, repeated 3 - 4 times to remove TFA. Lastly, the precipition was dissloved in $200 \mathrm{~mL}$ ultrapure water [14].

The silica gel plate was activated at $110^{\circ} \mathrm{C}$ for $30 \mathrm{~min}$, and $5 \mathrm{mg} / \mathrm{mL}$ standard solution or the solution of PP1, PP2 were spotted. The sample volume was 0.5 $\mathrm{mL}$. After drying, chromatography was carried out in the expansion agent. The proportions of liquid were ethyl acetate:methanol:acetic acid:water $=12: 3: 3: 2$. After spraying the chromogenic agent, the silica gel plate was placed at $150^{\circ} \mathrm{C}$ for $5 \mathrm{~min}$, the migration distance was measured according to the spots, and the mobility (RF) was calculated. The chromogenic agent was $1 \%$ hydrochloric acid, $2 \%$ aniline, $2 \%$ of diphenylamine, and $8.5 \%$ of phosphoric acid in acetone.

\subsubsection{Determination of Molecular Weight of Polysaccharides by Gel Method}

With the Sephadex G-75 column, the mobile phase was $0.1 \mathrm{M}$ of $\mathrm{NaCl}$. The $10 \mathrm{t}$, $20 \mathrm{t}, 50 \mathrm{t}, 70 \mathrm{t}, 100 \mathrm{t}$ and $200 \mathrm{t}$ of dextran standard samples were entered the chromatographic column, and measured the elution volume, named Ve, then 
determined water column volume V0 by measuring the blue glucose with 2 million molecular weight. The standard curve was make out, with $\mathrm{Ve} / \mathrm{V} 0$ as the ordinate and logarithm of molecular weight as the abscissa. The polysaccharide components were used to determine Ve of elution volume under the same conditions, and the molecular weight was obtained according to the standard curve.

\section{Results and Analysis}

\subsection{Purification of Polysaccharides from Pomegranate Flowers}

After the extraction of crude polysaccharide by sevage method, the content of protein was $1.03 \%$ in polysaccharide, and the retention rate o was $58.14 \%$. Using macroporous resin to remove pigment, and dialysis method to remove small molecular impurities, DEAE-52 cellulose column to separate polysaccharides, the gradient elution curve was shown in Figure 1. As shown in Figure 1, the two prominent symmetric peaks indicated that polysaccharides from pomegranate flowers were separated into two components. According to the order, the two peaks recorded as polysaccharide 1 and 2 (PP1; PP2). The protein contents of two components closed to 0 , determined by coomassie brilliant blue G250 method. Furthermore, in the UV absorption spectra of PP1 and PP2 shown in Figure 2, the obvious absorption peaks can be observed around $200 \mathrm{~nm}$, which were characteristic absorption peaks of polysaccharides. These results indicated that PP1 and PP2 were pure, without pollution of nucleic acid or protein.

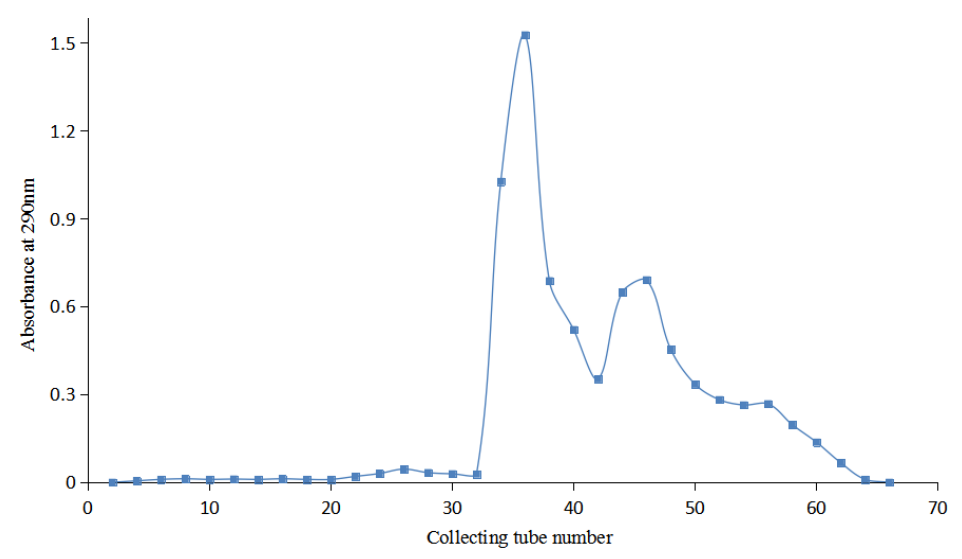

Figure 1. The elution curve of polysaccharides from pomegranate flowers.

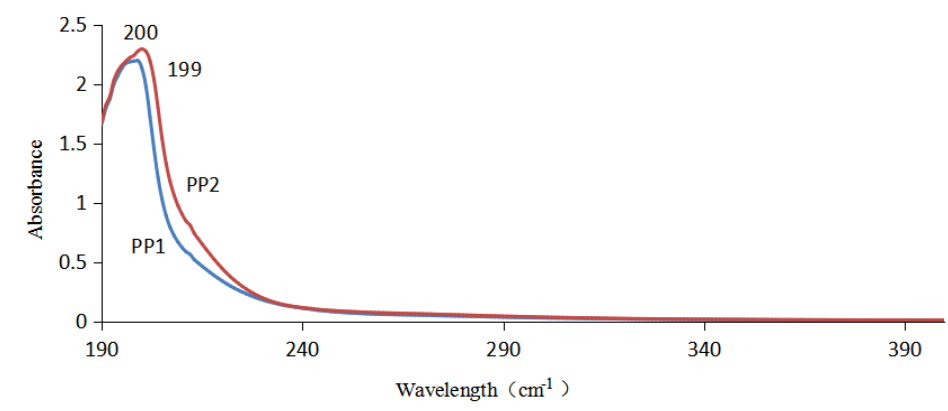

Figure 2. The UV scanning curve of PP1 and PP2. 


\subsection{Basic Physicochemical Properties of PP1 and PP2}

PP1 was white flocculent solids, soluble in water, aqueous solution was colorless clear liquid; PP2 was popcorn flocculent solids, slightly soluble in water, aqueous solution was colorless popcorn clear liquid. The two compounds were not soluble in ethyl acetate, ethanol, acetone, ether, n-butanol and other organic solvents. The phenol sulfuric acid reaction was positive in both of them, and the contents of uronic acid were $57.4 \%$ in PP1 and 27.5\% in PP2, which indicated that both of them were acidic polysaccharides. The iodine potassium iodide reactions of PP1 and PP2 were negative, indicating that the samples were different with starch. The data are shown in Table 1.

\subsection{Monosaccharide Composition of PP1 and PP2}

Analysing the results of silica gel chromatography, the specific migration rate of each monosaccharide standard and the acidolysis products of PP1 and PP2 were shown in Table 2. From the color spots and migration speed, it can be concluded that the monosaccharide components of PP1 and PP2 contained arabinose and galactose.

\subsection{Infrared Spectrum Analysis of PP1 and PP2}

The infrared spectra of PP1 and PP2 were shown in Figure 3. The functional groups in monosaccharide molecules were mainly hydroxyl and carbon hydrogen bonds, the absorption peaks of the whole spectrum were less, and most of them were wide and blunt.

As shown in Figure 3, the infrared absorption spectra of the two components were consistent, but with different absorption intensity. In $3400-3200 \mathrm{~cm}^{-1}$ range, the absorption of PP1 was strong and broad, the large and intense bands near $3380 \mathrm{~cm}^{-1}$ were the absorption peak of $\mathrm{O}-\mathrm{H}$ which overlaps with the stretching vibration absorption peak of N-H bond [1];2927 $\mathrm{cm}^{-1}$ and $2857 \mathrm{~cm}^{-1}$ were the stretching vibration absorption peaks of $\mathrm{C}-\mathrm{H}$, which were called characteristic absorption peaks of polysaccharides together with the $\mathrm{OH}$ absorption peak at $3380 \mathrm{~cm}^{-1}$ [15]; $\mathrm{C}=\mathrm{O}$ stretching vibration absorption peak of $\mathrm{COOH}$ at 1722 $\mathrm{cm}^{-1} ; 1621 \mathrm{~cm}^{-1}$ was the $\mathrm{N}-\mathrm{H}$ variable angle vibration absorption peak of first and second class amino; the absorption peak at $1406 \mathrm{~cm}^{-1}$ (PP1) and $1423 \mathrm{~cm}^{-1}$ (PP2) were attributed to $\mathrm{C}-\mathrm{O}$ stretching vibration absorption peaks of carboxyl;

Table 1. Basic physicochemical properties of polysaccharides.

\begin{tabular}{ccccccc}
\hline \multirow{2}{*}{ Groups } & Surface & Water & $\begin{array}{c}\text { Organic } \\
\text { solvent }\end{array}$ & $\begin{array}{c}\text { Shenol sulfuric } \\
\text { acid reaction }\end{array}$ & $\begin{array}{c}\text { The uronic } \\
\text { acid } \\
\text { content/\% }\end{array}$ & $\begin{array}{c}\text { I-IK } \\
\text { reaction }\end{array}$ \\
\cline { 3 - 7 } PP1 & $\begin{array}{c}\text { White } \\
\text { flocculent }\end{array}$ & $\begin{array}{c}\text { Soluble in cold } \\
\text { water }\end{array}$ & Insoluble & Positive & 57.4 & Negative \\
PP2 & $\begin{array}{c}\text { Pale yellow } \\
\text { flocculent }\end{array}$ & $\begin{array}{c}\text { Slightly soluble } \\
\text { in hot water }\end{array}$ & Insoluble & Positive & 27.5 & Negative \\
\hline
\end{tabular}


The absorption peak at $1142 \mathrm{~cm}^{-1}$ was the $\mathrm{C}-\mathrm{O}$ absorption peak on the ring; At $1102 \mathrm{~cm}^{-1}$ and $1020 \mathrm{~cm}^{-1}$ were two variable angle vibrational absorption peaks of the alcohol hydroxyl radical; Absorption peaks at $895 \mathrm{~cm}^{-1}$ indicate that both PP1 and PP2 have beta glycosidic bonds; The absorption peak at $855 \mathrm{~cm}^{-1}$ was characteristic of alpha difference structure [16], so it was presumed that PP1 and PP2 also contained alpha glycosidic bonds. The absorption peak of $\mathrm{D}$ grape sugar ring [17] was $778 \mathrm{~cm}^{-1}$, so it could be confirmed that the monosaccharide component contained galactose; the absorption peaks at $1240 \mathrm{~cm}^{-1}-1.850 \mathrm{~cm}^{-1}$ and $820 \mathrm{~cm}^{-1}$ indicated that the two components contained sulfuric acid group, proved that the PP1 and PP2 were acidic polysaccharides.

\subsection{Molecular Weight Identification of PP1 and PP2}

The standard curve of dextran standard was $y=-2.8061 \times 16.199\left(R^{2}=0.9999\right)$. The outer water volume of dextran column was $14.4 \mathrm{~mL}$, and the elution volume and the molecular weight range of PP1 and PP2 were shown in Table 3. The elution peaks of PP1 were wider, and there were some miscellaneous peaks in the corresponding PP2 peaks. The elution peaks of PP2 were relatively narrow, and with miscellaneous peaks corresponding to PP1. This showed that the two components could not be separated completely, and PP1 was the main component.

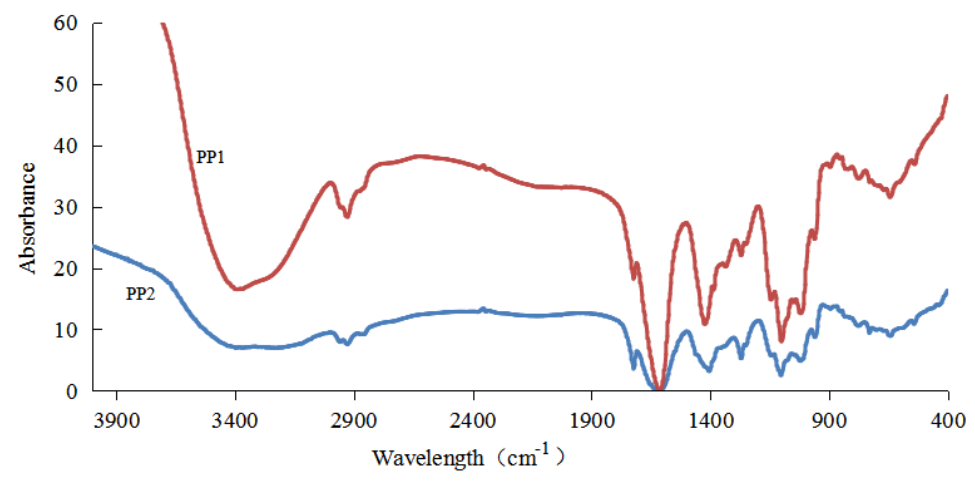

Figure 3. The IR scanning curve of PP1 and P2.

Table 2. The color and chromatographic mobility of each component.

\begin{tabular}{ccccccccccccc}
\hline \multicolumn{1}{c}{ Monosaccharide standard } & & & PP1 & & PP2 \\
\hline rhamnose & xylopyranose & mannose & arabinose & galactose & fructopyranose & glucose & Spot 1 & Spot 2 & Spot 1 & Spot 2 \\
\hline $\begin{array}{c}\text { light } \\
\text { green }\end{array}$ & $\begin{array}{c}\text { sky } \\
\text { blue }\end{array}$ & $\begin{array}{c}\text { Pale } \\
\text { Yellow-Green }\end{array}$ & $\begin{array}{c}\text { light } \\
\text { blue }\end{array}$ & $\begin{array}{c}\text { Pale } \\
\text { Yellow-Green }\end{array}$ & $\begin{array}{c}\text { brick } \\
\text { red }\end{array}$ & $\begin{array}{c}\text { Pale } \\
\text { Yellow-Green }\end{array}$ & $\begin{array}{c}\text { Pale } \\
\text { Yellow-Green }\end{array}$ & $\begin{array}{c}\text { light } \\
\text { blue }\end{array}$ & $\begin{array}{c}\text { Pale } \\
\text { Yellow-Green }\end{array}$ & $\begin{array}{c}\text { light } \\
\text { blue }\end{array}$ \\
\hline 0.7857 & 0.6963 & 0.6296 & 0.6489 & 0.5797 & 0.6187 & 0.6141 & 0.5928 & 0.6446 & 0.5974 & 0.6439 \\
\hline
\end{tabular}

Table 3. Molecular weight of polysaccharides from pomegranate flowers.

\begin{tabular}{ccc}
\hline Component & elution volume $(\mathrm{ml})$ & molecular weight \\
\hline PP1 & $39.71 \mathrm{~mL}$ & $6.16 \times 10^{4}( \pm 6.6 \%)$ \\
PP2 & $33.06 \mathrm{~mL}$ & $9.01 \times 10^{4}( \pm 3.2 \%)$ \\
\hline
\end{tabular}




\section{Conclusion}

In this study, the physical and chemical properties of polysaccharides from pomegranate flowers were studied by various physical and chemical methods. The results showed that PP1 and PP2 were acidic polysaccharides, soluble in water, insoluble in organic solvents, without starch, nucleic acids, proteins and other substances; which mainly consisted of the arabinose and galactose; contained hydroxyl, carboxyl, amino, hydroxyl, sulfate base, beta glycosidic bond and glycosidic bond structure. The molecular weight of PP1 and PP2 was $6.16 \times 10^{4}$ $( \pm 6.6 \%)$, and $9.01 \times 10^{4}( \pm 3.2 \%)$, respectively. The results laid a foundation for the further development and application of polysaccharides from pomegranate flowers.

\section{Acknowledgements}

We are grateful for the financial support provided by the Key Research and Development Projects of Shandong Province (No. 2017GSF21118).

\section{Conflicts of Interest}

The authors declare no conflicts of interest regarding the publication of this paper.

\section{References}

[1] Zhang, X.J. (1988) Natural Pharmaceutical Chemistry. People's Medical Publishing House, 3-16.

[2] Huang, T.H.W., Peng, G., Kota, B.P., Li, G.Q., Yamahara, J., Roufogalis, B.D. and Li, Y. (2005) Pomegranate Flower Improves Cardiac Lipid Metabolism in a Diabetic Rat Model: Role of Lowering Circulating Lipids. British Journal of Pharmacology, 145, 767-774. https://doi.org/10.1038/sj.bjp.0706245

[3] Rukeyamu-Shadeke (1993) Uighur Common Medicinal Herbs. Xinjiang Science and Technology and Health Press, 128-129.

[4] Li, Y.H., Qi, Y.H. and Huang, T.H..W. (2008) Pomegranate Flower: A Unique Traditional Antidiabetic Medicine with Dual PPAR- $\alpha / \gamma$ Activator Properties. Diabetes Obesity \& Metabolism, 10, 10-17.

[5] Ya, B.Q. and Zhang, J.G. (2004) A New Theory of Cancer-The Theory of Many Candies Loss. China New Medicine, 6, 19-22.

[6] Ren, P., Ruan, X.W. and Chen, W.F. (2004) Extraction Process of Pomegranate Pollen Polysaccharide. Food Research and Development, 5, 85-86.

[7] Liu, S.R. (1988) Immunopotentiating Agents-Introduction of Polysaccharides. West China Journal of Pharmaceutical Sciences, 3, 164-166.

[8] Zhang, S. and Xv, Z.Y. (1996) Advances in Research on Biological Activity of Polysaccharides. Chinese Journal of Biochemical and Pharmaceutics, 6, 272-274.

[9] Ke, C.L., Li, Z.M., Li, B.Y., Qian, S.Q. and Zhang, B. (2015) Study on Optimization of Extraction Conditions for Polysaccharide from Pomegranate Flowers and Its Antioxidant Activities. Science and Technology of Food Industry, 8, 286-304.

[10] Zhang, Q. and Zhang, T.M. (2004) Phenol Sulfuric Acid Colorimetric Method for the Determination of Polysaccharide Content. Shandong Food Science and Tech- 
nology, 7, 17-18.

[11] Wang, X.P. and Xing, S.L. (2009) Study on the Determination of Protein Content of Coomassie Brilliant Blue Method. Tianjin Chemical Industry, 23, 40-42.

[12] Qi, H.L., Lu, G. and Su, T.F. (2000) Removal of Protein by Sevag Method and Studies on Proteins in Polysaccharides. Tianjin Chemical Industry, No. 3, 20-21.

[13] Chen, Q.Q., Wan, Q., Wang, Z.Z., et al. (2012) A Method for Determination of the Uronic Acids in Polysaccharides Isolated from Panax Ginseng. Chinese Journal of Experimental Traditional Medical Formulae, 18, 121-124.

[14] Zhang, R.Y., Hu, L.L. and Wu, J.X. (2012) Improvement of the Thin Layer Chromatography of Monosaccharide. Laboratory Science, 15, 45-49.

[15] Zhang, Y.L., Huang, L.X., Zhang, C.H., et al. (2016) Purification and Structural Analysis of Polysaccharides from Fruits of Zizyphus jujube Mill. cv. Hupingzao. Food Science, 37, 33-37.

[16] Wang, Y., Wu, S.G., Zhou, J., et al. (2000) Studies of Extraction and Purification Technique of RBS and Anti-Tumor Effect Related to the Poly-Saccharide. Life Science Research, 4, 273-277.

[17] Zhang, W.J. (1988) Biochemical Research Technique of Compound Polysaccharides. Shanghai Science and Technology Press, 121-128. 